\title{
Design and development of devices based on digital slurry pipeline management system
}

\author{
XueyongWang ${ }^{1, ~ a}$, Hongwu $\mathrm{Xu}^{2, \mathrm{~b}}$, Chunlei $\mathrm{Pan}^{1, \mathrm{c}}$, Guangyue $\mathrm{Pu}^{1, \mathrm{~d}}$ \\ 1Yunnan Da Hongshan Pipeline Co., Ltd., Kunming, 650504, China \\ 2Faculty of Information Engineering and Automation, Kunming University of Science and \\ Technology, Kunming, 650500, China

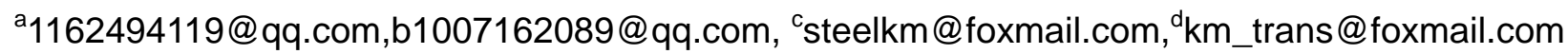

Keywords: equipment management system; equipment management and maintenance; the normal operation

\begin{abstract}
In recent years, development of mineral pipeline is rapid, which is one of the best way to solve the question fine iron ore output in the complex terrain of the western china. Application practice shows that the method of mineral pipeline transportation solved a series of defect from other transportation mode including waste resource etc. Equipment management and maintenance are foundation work of pipeline transportation. They act pivotal role in the production of iron ore slurry pipeline length, only strengthen the management and maintenance of equipment management system to maximize the performance of equipment, to ensure the pipeline business production operate normally. Equipment maintenance management is an important component of the equipment management system. Improvements of equipment maintenance management will play an important role in consummating equipment management system.
\end{abstract}

\section{Introduction}

Device management is the management work of the equipment life cycle of the whole process, including the selection of equipment, proper use of equipment, maintenance and repairing of equipment and renovation of equipment in the whole process.

From two fundamentals of goods and capital, Equipment movement process can be divided into two basic movement patterns, namely capital movement patterns and goods movement patterns of the device. Material movement patterns of equipment, from the fundamentals of the physical form of the device, is a whole process beginning the device's research, design and manufacture or the device being into factory, during use, maintenance, updating and renovation of device to retirement and exit the production field., the management of this process is called technical management of equipment; capital movement patterns of the device, from the view of the capital value, form of the device , include the initial investment, operating costs, maintenance costs, depreciation, income and renovation measures etc, This level of management process is called economic management of devices. Device management include technical management equipment and economic management device, are both unify and comprehensive and management, stressing on any one level of management is not the final requirement of modern equipment management ${ }^{[1]}$.

Dahongshan fine iron ore pipeline transportation equipment management system includes equipment running state management, equipment maintenance management, equipment inspection management, data base of equipment failure. Equipment operating status of each node includes equipment operating conditions, as well as start and stop times of the main pump station. Equipment management system analyze mainly some statistical device information include equipment operating rate, down rate, uptime, downtime, the main pump start and stop times for each station, transport ore, transport of water, each team equipment operation conducted, based on the complete above information. Equipment maintenance management, providing remote management platform for each node, daily, monthly, annual overhaul project declaration, examination and approval, at the same time statistics on the maintenance project of major equipment, provide the analysis basis for health diagnosis of main equipment. Equipment 
inspection management mainly records some data of major equipment inspection and standardized inspection operate, providing basis of health diagnostic devices for analysis ${ }^{[2]}$.

\section{System module node}

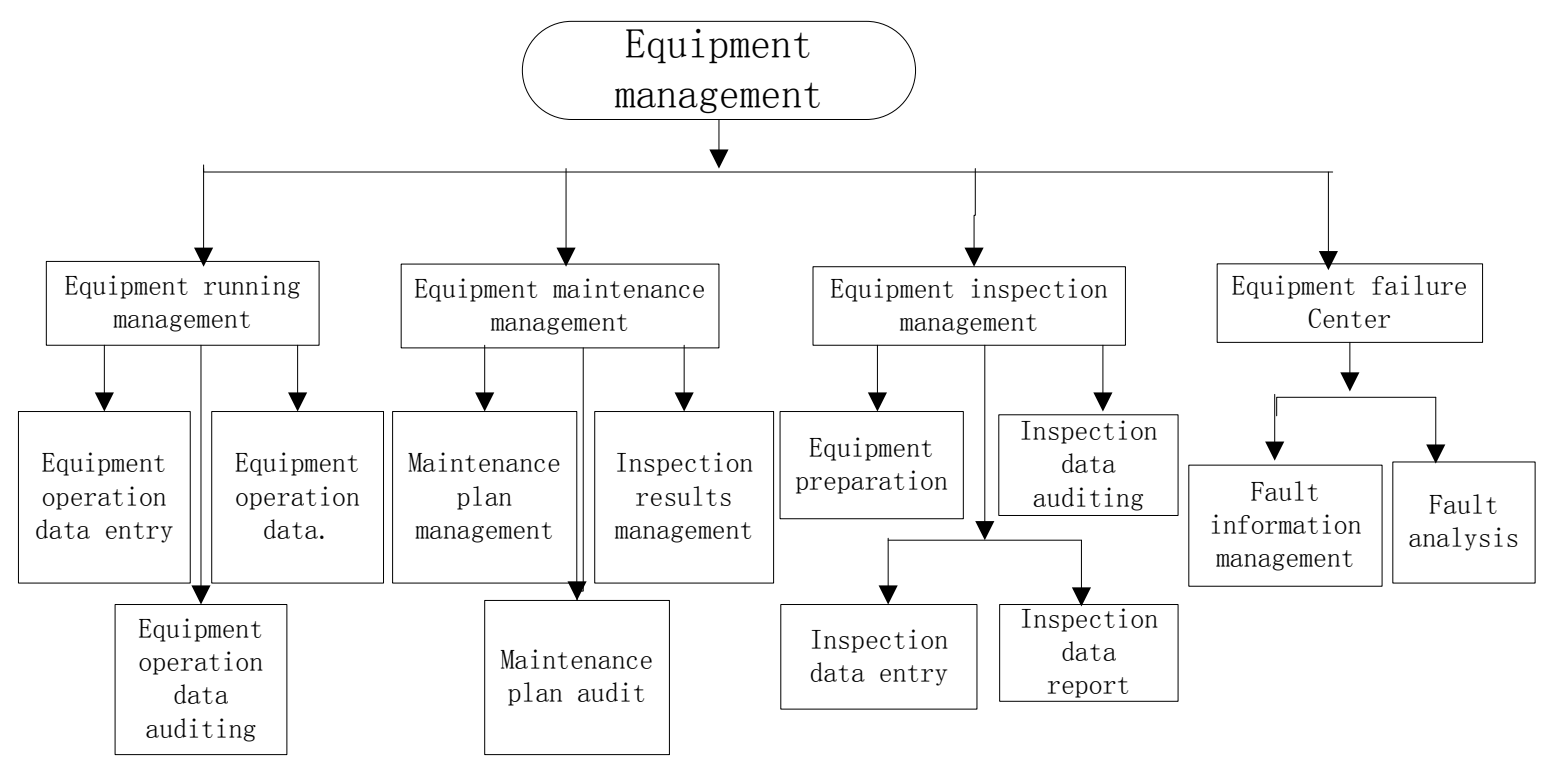

\section{(1) Equipment Operation and Management}

Fig 1 Device Management Structure

This module records mainly each node equipment belong to company operating rate, downtime rate, run time, down time and each station main pump start and stop times and other data statistical analysis.

Operational processes: The unit of equipment operation data entry; then determine whether the data need to be modified, the data need to be modified by the leadership of the work area, and then confirm the data, adding a signature to the system; the data not to need to modify directly to be confirmed by the work area leadership, adding a signature to the system; finally generated day Week month Year reports, equipment operation rate, down rate, running time, downtime statistical analysis report, the stations of the main pump start and stop times and transportation of ore, water, statistical analysis, equipment operation rate and spare parts attrition rate statistical analysis, compare analysis of each class equipment operating conditions.

\section{Main Report:}

Equipment operating status reports

Equipment operation rate, down rate, running time, downtime statistical analysis reports

Each station pump start and stop times and ore quantity, water transport data statistics and analysis report

The operation rate of the equipment and spare parts, the loss rate of statistical analysis report

Equipment operating status of each team statistical analysis reports

(2) Equipment Maintenance Management The module provided a remote management platform for maintenance project declaration, examination and approval of each node daily, monthly, annual, while some of the major equipment overhaul project statistics, provide basis of health diagnosis equipment to analysis. In addition, the implementation of the contents of maintenance projects, the implementation of effective personnel records, so that the quality of maintenance and repairing projects persons responsible for traceability, but also enables maintenance personnel statistics for each node involved in maintenance projects in order to grasping the work of competent leadership and efficient sector in humans. Establishing equipment maintenance management system, you can create maintenance knowledge base, providing the basic data for the next support expert systems 
and knowledge systems.

Operation process: first submit equipment maintenance program or devices rummage plan; then determine whether need to modify plans and examine whether pass ; each unit by performing the procedure after entry plan; the first aspect after execution entry program will generate various reports, the second aspect to determine whether to enter the device fault management center; into the device fault management center for the equipment to malfunction after grading, and finally into the equipment failure knowledge base.

Main Report:

Complete overhaul Fact Sheet

Rummage completion table

Statistics overhaul costs

Rummage cost statistics

\section{(3) Equipment Inspection Management}

Statistical analysis of some major equipment inspection data and the formation of trend analysis, provide the basis for health diagnosis equipment.

RFID technology can be used during equipment inspection, inspection personnel must arrive at the device location and read data via RFID terminal. Meanwhile registration equipment checks on mobile devices, checking the completion and import the data through a unified interface to the system. Do point inspection staff to check the rate for $100 \%$.

Equipment inspection management system that can query and equipment operating data linkage, directly download device-related data and according to the equipment operating data divided the device into two level: general inspection level and key inspection level.

The main operational processes: first of all, by inspector apply for inspection equipment; then equipment maintenance and operation of historical data download; write data to system in the field, and determine whether the data need to be modified; data to be modified by the district leaders were modified, then confirm the data, and adding a signature to the system; the data not need to modify should be confirmed by leadership of the work area the system ,adding a signature; finally claiming various reports.

Main Report:

Day, Week, Month, Year Inspection Report

Personal inspection reports completion of the statistical analysis

Complete inspection team Statistical Analysis Report

Statistical analysis of inspection reports consumable costs

(4) Device Fault Management Center Major equipment or the needing for fault management and analysis of equipment failure statistics, and effectively improve the trouble shooting methods, based on the knowledge can be established according to the fault characteristic failure to provide an effective learning platform for other sites or employees, enhance knowledge reuse.

The grading equipment failure information input, generating the corresponding data report.

Main Report:

Week Month Year equipment failure statistical analysis reports

Equipment failure location information Statistical Analysis Report

Statistical analysis of the cost of equipment failure reports

Cause of equipment failure Statistical Analysis Report

\section{Equipment Maintenance Program Management Process Analysis}

In the traditional manual management, information collection and feedback show slow speed, data distortion, severe loss, resulting in all aspects of device managements disjointed, inaccurate analysis of various indicators, impact improving equipment management level ${ }^{[3]}$. Therefore, equipment maintenance program management is through the combination of information technology and management techniques to complete the repair work on the equipment, improving work efficiency, promoting the modernization of equipment management to achieve in order to 
improving production technology and quality of product, reducing consumption and ensuring safe production, increasing the purpose of economic benefit.

Dahongshan fine iron ore pipeline maintenance is a complex program, first of all, to develop group work area equipment, dewatering station, Dongchuan branch preparation equipment maintenance plan; validation through production management department, assembly maintenance plan, to judge whether through , if not returned and then must be re-designated, after approval by the manager of the company in charge of maintenance plan; through competent manager approval before they can be reported to the energy conservation center, while incorporating months production and operation plans; overhaul preparation, organization and implementation; then the to accept the overhaul project acceptance, not to be re-requested by rectification, each station must fill in real-time equipment maintenance costs of the project and after the adoption of the tables; production management department gave approval, aggregate, not through the validation will have to re-report; through newspaper company in charge of the leadership of approval after approval, after the adoption of energy conservation reported, after the adoption of that plan is completed. The following table shows the A, B line of the main pump data.

Table $1 \mathrm{~A}$, B line of the main pump operating data

\begin{tabular}{|c|c|c|c|c|c|c|c|}
\hline $\begin{array}{l}\text { Line } \\
\text { name }\end{array}$ & $\begin{array}{l}\text { main } \\
\text { pump } \\
\text { name }\end{array}$ & $\begin{array}{c}\text { main } \\
\text { pump } \\
\text { speed (\%) }\end{array}$ & $\begin{array}{l}\text { main } \\
\text { pump } \\
\text { stroke( } \\
\text { 次/分) }\end{array}$ & $\begin{array}{l}\text { main } \\
\text { pump } \\
\text { flow } \\
(\mathrm{m} 3 / \mathrm{h})\end{array}$ & $\begin{array}{c}\text { main pump } \\
\text { total } \\
\text { stroke (次) }\end{array}$ & $\begin{array}{c}\text { main } \\
\text { pump } \\
\text { entrance } \\
\text { pressure } \\
\text { (Kpa) }\end{array}$ & $\begin{array}{c}\text { main } \\
\text { pump outlet } \\
\text { pressure } \\
\text { (Kpa) }\end{array}$ \\
\hline main & A pump & 0 & 0.10 & 0.24 & 116011968 & 698 & 8000 \\
\hline pump & B pump & 0 & 0.10 & 0.24 & 91325584 & 682 & 8000 \\
\hline A line & C pump & 0 & 0.10 & 0.24 & 55526440 & 514 & 7600 \\
\hline main & D pump & 48 & 21.20 & 73.00 & 1066692 & 843 & 18056 \\
\hline pump & E pump & 48 & 20.84 & 72.00 & 19470 & 874 & 18063 \\
\hline B line & F pump & 48 & 21.19 & 73.00 & 10272 & 856 & 18037 \\
\hline
\end{tabular}

\section{Conclusion}

Device management as an important part of enterprise management, enterprise strategy implementation costs and achieve core saving efficiently, but also the decision-critical enterprise market competitiveness and resilience lies ${ }^{[4]}$. In order to better adapting to the new situation, we need to study the problems and deficiencies in equipment Dahongshan pipeline company management exist, and making targeted improvements to improve the company's device management ${ }^{[5]}$, the equipment management more responsive to the needs of future advanced devices. To increase Dahongshan slurry company in the same enterprise core competitiveness, while improving its profitability.

\section{Acknowledgement}

This work is supported by National Natural Science Foundation of China (No. 51169007), Science \& Research Program of Yunnan province (No.2011CI017 \& 2012CA022\&2013DH034). 


\section{References}

[1]ZhouWenbiao. Modern Management Theory and Methods[M]. Shanghai: Tongji University Press.1995:20-28.

[2]Zhu Yunping.Application and Innovation of “Dianjian”Institution in Mechanical and Electronic Equipment Management of Colliery. Coalmining Technology. 2008,13(5):102-103.

[3]JIAO Long, LUO Jing-chun. Design and Analysis of Equipment Maintainauce Management Control Information System[J]. Gansu Metallurgy. 2011,33(04):110-112+115.

[4]Ning Bo,Ling Xiao,Zhang JinJun,Wang Yi.Study on laying technology of products pipeline along with hot crude pipeline in one ditch. Acta Petrolei Sinica. 2007,28(05):149-152.

[5]Zhao Tao,Mao Hua,Liu Shu.Theoretical Architecture and Development Trends of Plant Management[J]. Industrial Engineering Journal. 2001.4(2):1-4. 